\title{
Competencia Intercultural en Secundaria: Miradas entrelazadas de profesores y estudiantes hacia personas de otras culturas y creencias
}

\author{
Intercultural Competence in Secondary School: Intertwined views of teachers and \\ students towards people of other cultures and beliefs
}

\author{
Miguel-Ángel Ballesteros-Moscosio \\ e-mail: miguelanba@us.es \\ Universidad de Sevilla. España \\ Estefania Fontecha Blanco it \\ e-mail: estefania_fontecha@hotmail.es \\ Universidad de Sevilla. España
}

\section{Resumen}

La realidad multicultural cada vez más evidente en nuestra sociedad, se traslada, cómo no, a nuestros centros educativos. Este hecho pone en evidencia el nivel formativo de los distintos agentes que forman parte de la comunidad educativa con relación al grado de adquisición de la denominada "competencia intercultural", como estrategia para dar respuesta efectiva a la diversidad en las aulas. El estudio que aquí presentamos se centra en el análisis de dicha competencia intercultural en el I.E.S. Miguel de Cervantes, centro educativo sevillano, desde la perspectiva de los estudiantes $(\mathrm{N}=76)$ y los docentes $(\mathrm{N}=9)$. Este centro se ubica en un barrio con altas tasas de población de orígenes culturales diversos. Para su realización, optamos por un diseño híbrido, empleando de manera combinada entrevistas y cuestionarios, previo análisis de los documentos oficiales del centro. Los resultados indican la necesidad de desarrollar un currículum multicultural para facilitar la óptima integración de los distintos colectivos presentes en el centro, ya que el alumnado presenta cierto grado de adquisición de esta competencia al tiempo que muestra actitudes prejuiciosas y estereotipadas hacia las personas de otras culturas y creencias. Asimismo, la formación de los docentes en esta cuestión aparece como un elemento crucial para la mejora de los procesos socioeducativos en el centro.

Palabras clave: competencias del docente; educación intercultural; multiculturalismo; cultura; integración escolar.

\section{Abstract}

The multicultural reality is more evident in our society, it is transferred to our educational schools. This fact highlights the formative level of the different agents which are part of the educational community in relation to the acquisitional degree of the so-called "intercultural competence", as a strategy given by an effective response to diversity in the classrooms. The study presented here is focused on the analysis of this intercultural competence in the I.E.S. Miguel de Cervantes, Sevillian school, from the perspective of students $(\mathrm{N}=76)$ and teachers $(\mathrm{N}=9)$. This school is located in a neighborhood with a high population rate of diverse cultural origins. For its realization, we opted for a 'hybrid' design, using combined interviews and questionnaires, after analyzing the official documents of the center. The results indicate the needs to develop a multicultural curriculum to facilitate the optimal integration of the different groups presented in the school, since the students show some acquisition degree of this competence while it is shown prejudiced and stereotyped attitudes towards people of other cultures and beliefs. Likewise, the training of teachers in this issue appears as a crucial element for the improvement of socio-educational processes in the school.

Keywords: teacher competences; intercultural education; multiculturality; culture; school integration.

Recibido / Received: 23-03-2018

Aceptado / Accepted: 01-10-2018

Cómo referenciar este artículo / How to reference this article:

Ballesteros Moscosio, M.A., \& Fontecha Blanco, E. (2019). Competencia Intercultural en Secundaria: Miradas entrelazadas de profesores y estudiantes hacia personas de otras culturas y creencias. Tendencias Pedagógicas, 33, 18-36. doi: 10.15366/tp2019.33.002 


\section{Introducción}

En los últimos años la realidad multicultural de la sociedad española cada vez es más evidente. Nuestro país se ha convertido en un lugar de acogida para personas de otras culturas y creencias, lo cual ha puesto en evidencia la necesidad de la integración de estas personas, sin que ello suponga el desarraigo cultural. La educación y la escuela, como institución educativa por antonomasia, han de dotar a la ciudadanía de las competencias necesarias para el acercamiento entre las personas, independientemente de su origen, color, religión, etc. En este contexto se hace necesaria una apuesta clara por la educación en la competencia intercultural no solo entre los escolares, también entre los profesionales de la educación, que permita luchar activamente contra la perpetuación de estereotipos y prejuicios hacia otras culturas, para que sean capaces de relacionarse y comunicarse con personas de otras culturas (Malazonia, Maglakelidze, Chiabrishvili y Gakgeladze, 2017).

Mantener relaciones o conexiones con otras culturas requiere tener competencias sociales e interculturales (Martinez, 2018), lo que nos lleva a considerar la necesidad de que los centros educativos deben convertirse en espacios que verdaderamente lo posibiliten. En su seno se propician interacciones y situaciones donde se pueden erradicar y desmontar prejuicios y estereotipos asumidos culturalmente, para así conseguir una sociedad que sea de todos y para todos. Este objetivo no puede quedarse en esfuerzos aislados o en una simple declaración de intenciones sino que ha de fijar la actuación y compromiso de cada institución social para lograr la inclusión de todas las culturas o, lo que es lo mismo, la interculturalidad real (Pech y Rizo, 2014).

\section{Cultura, multiculturalidad e interculturalidad}

Aceptar la diversidad en relación al fenómeno migratorio supone considerar a nuestra sociedad como una realidad heterogénea, esto nos remite a conceptos tales como "multiculturalidad" o "interculturalidad", "etnicidad", "identidad", "prejuicio" etc., todos ellos en estrecha relación con un concepto transversal como es el de cultura. Así, desde una visión educativa, puede entenderse la cultura como la totalidad de las creencias aprendidas, las herramientas y tradiciones compartidas por un grupo humano con el objeto de dar continuidad, orden y significado a sus vidas; reflejando las experiencias y productos acumulados por un colectivo (García y Pulido, 1992); o como un sistema conceptual y de valores que incluyen las creencias y expectativas, además de los patrones, rutinas, conductas y costumbres creadas y mantenidas por un colectivo, siendo utilizadas y modificadas para este colectivo (Figueroa, 1993). García (2005) y Sáez (2006), haciendo referencia directa a cómo un colectivo interpreta la realidad en la que se desenvuelve, la ven como fruto del aprendizaje, adquirida a través del proceso humano de socialización; con un carácter dinámico que da sentido y significado a la realidad a la que se adapta, en evolución permanente, permitiendo a los grupos sociales hacer frente a los problemas de la vida.

Todo lo anterior nos lleva a la consideración de una visión diversa de la cultura, coexistente con otras culturas coincidiendo en una misma zona geográfica (Quilaqueo y Torres, 2013, p.286). Hemos de considerar entonces el concepto de multiculturalidad fundamentado en varios elementos (Abdallah-Pretceille, 2001):

1. Prioridad a un grupo de pertenecía.

2. Una localización espacial de las diferencias que pueden traducirse en la creación de barrios étnicos y de sus variantes.

3. Una jurisdicción específica y compleja que garantice los derechos de cada cual.

4. Un reconocimiento del relativismo cultural.

5. La expresión de las diferencias en el escenario público.

Realmente cualquier país es, por definición, multicultural, ya que en un mismo espacio conviven grupos de diversas culturas, y eso incluye la diversidad de lenguas y de creencias, por lo que también podemos suponer que la multiculturalidad da por hecho una convivencia positiva y de aceptación de las personas inmigrantes, que en la mayoría de las ocasiones no responde a la realidad. El fenómeno multicultural, se plantea a partir del principio de reconocimiento mutuo como base de la convivencia. Se hace 
necesario aprender a convivir y a conciliar intereses individuales y colectivos con otros grupos culturales que, en algunos casos, pueden presentar grandes diferencias. Supone apostar, por tanto, por una convivencia democrática que exige el diálogo, la apertura, y el reconocimiento mutuo de las diferentes culturas (Cabrera, 2002, p. 97). La multiculturalidad genera la necesidad de reconocerse mutuamente, para así establecer unos valores o principios comunes en los que se sustente una convivencia, desde el respeto hacia las diferencias culturales, considerándolas como un valor en sí mismo.

Otro concepto asociado a los anteriores sería el de Interculturalidad, muchas veces confundido con el anterior, como señala García (2005, p.95):

\begin{abstract}
"Mientras que el termino multicultural debe emplearse cuando se hace referencia a la yuxtaposición espacial y temporal de unas culturas determinadas, la expresión intercultural sugiere la idea de una intervención que fomente el dialogo y el dinamismo entre las distintas culturas que nos guiará hacia una influencia y enriquecimiento mutuos. Por lo que la utilización del segundo de estos términos nos parece, desde un punto de vista educativo, más educada y ajustada a la realidad".
\end{abstract}

Supone asumir la asimetría entre las culturas y la aceptación e inclusión de saberes y practicas diferentes (Dietz, 2012). Las instituciones educativas son entonces las encargadas de formar ciudadanos para que puedan insertarse en el marco de unas reglas democráticas de convivencia común y aceptada para todos, y desde un prisma intercultural. En cualquier caso, la interculturalidad se da cuando las significaciones adquiridas por las personas de cualquier tiempo y espacio se reconocen mutuamente, de modo que significa respeto, intercambio, apertura, aceptación de valores y de los modos de la vida de los otros, sin por ello admitir acríticamente cualquier postulado de cultura, por muy arraigado que pueda ser (Escarbajal, 2009, p.103).

Podemos considerar la interculturalidad como la aceptación de las distintas culturas o creencias, convirtiéndose así en un valor en sí mismo, que tendría que ser compartido por toda la ciudadanía, ya que al fin y al cabo la interculturalidad supone convivir siendo conscientes de nuestros propios prejuicios. Y lo cierto es que no es una tarea fácil para el profesorado, ya que la realidad que nos rodea tiene un gran carácter etnocéntrico, o lo que es lo mismo centrado en la etnia de procedencia, lo que en consecuencia está determinado por la diferencia, que no hace más que obstaculizar el desarrollo de una sociedad intercultural. La interculturalidad se entendería desde la perspectiva democrática, crítica y global, superando el mutuo conocimiento y formación puntual (Morales, 2007, p.166).

\title{
3. La Educación como respuesta a la diversidad social: Competencia intercultural
}

Unos de los derechos de cualquier persona, y más en una sociedad global como la nuestra, es facilitar su plena integración en la sociedad a través del sistema educativo. Las instituciones educativas que contemplan la interculturalidad deben basar su actividad, en dicho objetivo. Esto significa necesariamente analizar y revisar sus prácticas educativas para conseguir una intervención intercultural eficaz. La educación desde una perspectiva intercultural intenta aprovechar la oportunidad que supone la diversidad y la multiculturalidad. Desde el ámbito educativo y a través de las prácticas de los docentes, se pretende que las personas de diferentes culturas y creencias se integren en la sociedad de acogida, pero además, que esa sociedad de acogida sea capaz de convivir y concebir la pluralidad cultural de manera positiva, desarrollando una Pedagogía de la acogida, no solo dirigida a las personas con diferentes bagaje cultural al nacional sino a toda la ciudadanía en su conjunto (Ballesteros-Moscosio, 2013). Uno de los retos que plantea la diversidad es conseguir que la Educación y la escuela ofrezcan la posibilidad de que todos los estudiantes puedan acceder a un currículum básico, común, ya que esto supondría contribuir a prepararlos para la participación democrática en un mundo complejo, diferente y asincrónico (Abdallah-Pretceille, 2001). En consecuencia, es necesario dotar a los centros educativos de un modelo intercultural, lo que necesariamente nos conduce al desarrollo y consideración de un nuevo concepto: la competencia intercultural. 
La idea de competencia hace referencia a un concepto polivalente, que se da en diversos contextos educativos, como recuerda Morales (2007), distinto de otros conceptos tales como inteligencia, conocimientos, actitudes, capacidades, etc. Como nos recuerda Delors (2000), además de las consideraciones relativas al saber, saber hacer o saber ser, estaría otra que sería la relacionada con saber convivir en sociedad, para lo cual es esencial el respeto a la diversidad. En este sentido, podemos deducir que las competencias son aprendizajes que poseen un carácter complejo, que se logran en un contexto determinado, pero que en definitiva son enseñanzas significativas que pueden ser modificadas y ampliadas a la largo de la vida, haciéndonos más competentes.

Así las competencias podemos entenderlas como un conjunto de habilidades, conocimientos y actitudes, que se ponen en marcha de forma diferente y en distintos contextos, ofreciendo la oportunidad de desarrollar y obtener otros aprendizajes. En consecuencia, la competencia intercultural supone un conjunto de capacidades concretas, como señala Aguado (1998, p. 93), referidas a:

- Actitudes positivas respecto a la diversidad cultural y ampliación de conocimiento acerca de costumbres y creencias de los otros.

- Habilidad comunicativa verbal y no verbal que permite comunicaciones afectivas en contextos donde dos o más culturas están en contacto. Reconocer y manejar la tensión generada en situaciones multiculturales ambiguas.

- Capacidad de reflexionar sobre la propia cultura, reconociendo cómo ésta influye en la forma en la que nos vemos a nosotros mismos y a los demás.

Estas capacidades permiten al estudiante desarrollarse con éxito en la sociedad multicultural actual, al permitirle superar la visión simplista de la cultura para considerarla de una manera amplia y dinámica.

De entre todas las definiciones del término educación intercultural se pueden distinguir dos tendencias. Una de ellas estaría formada por las destrezas sociales y la otra por el enfoque holístico. Según Villar (2008), ambas tendencias coinciden en los siguientes rasgos:

1. Es efectiva, en la comunicación con interlocutores con diferente bagaje cultural.

2. Es apropiada para actuar de modo correcto, en un contexto determinado.

3. Tiene un componente afectivo actuando desde la empatía, tolerancia, etc.

4. Tiene un componente cognitivo, mediante el conocimiento y reflexión sobre otras culturas, los prejuicios, estereotipos, etc.

5. Tiene un componente comunicativo, para entender signos verbales, no verbales, interpretar, etc.

Sea como fuere contempla una visión integral de la persona, no solo como individuo, también como sujeto social.

\section{El currículum intercultural como respuesta}

Con todo lo expuesto hasta el momento, podemos considerar sin lugar a dudas que los centros educativos son un contexto idóneo para desarrollar la competencia intercultural, para lo cual es necesario hablar de currículum intercultural, en el que a través de herramientas y metodologías de aprendizaje cooperativo se aborden contenidos curriculares desde una visión múltiple de conocimientos, tolerancia e igualdad. Es por ello que para hablar de centros educativos interculturales, es necesario que estos basen su labor en un currículum intercultural. En este sentido, como señala Pozuelos (2008, p.77) podemos distinguir diferentes grados de integración cultural en los centros de enseñanza. Encontramos así proyectos que persiguen facilitar el acceso a la cultura oficial (compensatoria), otros que proponen medidas encaminadas a incluir de forma circunstancial ciertas referencias a otras culturas sin que llegue a penetrar ni a cuestionar el currículum oficial y hegemónico (multiculturalidad blanda) y, por último, aquellas iniciativas que se proyectan con el 
propósito de incluir progresivamente el dialogo intercultural con intención de transformar el currículum hasta que sea representativo y justo con toda la comunidad (interculturalidad).

Obviamente, el desarrollo en estos términos de dicha competencia intercultural conlleva una mayor implicación profesional y formación de los docentes en los centros educativos, en la medida en la que la persona que reconoce las diferencias culturales favorece un proceso de intercambio y convivencia, generando un aprendizaje y enriquecimiento entre los individuos de las culturas que interactúan (Leiva, 2010). El profesional de la educación es considerado así un catalizador de los procesos de desarrollo social y cultural.

Un currículum intercultural introduce aportaciones que proceden de distintas culturas, de forma que puede ser compartido por todos y ayude a construir puentes entre las variadas corrientes que conviven en el contexto social. Comprende, en este sentido, una relación simétrica en la que surge una dinámica de enriquecimiento mutuo. Lo auténticamente significativo de la educación intercultural descansa en la interacción. Es decir, en la búsqueda del encuentro y el contacto entre personas de diferentes modos culturales (Sáez, 2006).

Consideramos importante la observación de que apostar por un currículum intercultural no es solo participar en iniciativas externas a la escuela, o realizar actividades interculturales puntuales, al igual que tampoco debe ser implantado solo en el caso de que haya presencia de estudiantes inmigrantes, puesto que la realidad que nos rodea es cada vez más diversa y plural. Es por esto que todos los centros tendrían que contar con un currículum intercultural para que los estudiantes puedan aprender a desenvolverse en una sociedad diversa por definición, en la que la normalidad se encuentra en el hecho de convivir con personas de otras culturas y creencias. Más que una realidad a reconocer, es una necesidad en sí misma.

\section{Metodología y diseño de investigación}

\subsection{Perspectiva}

El estudio que aquí presentamos se centra en el análisis de la competencia intercultural desde la perspectiva de los estudiantes y la visión que de éstos tienen los docentes, para determinar así el grado de incidencia de la misma en los procesos educativos desarrollados en el I.E.S. Miguel de Cervantes, centro educativo sevillano ubicado en un barrio con altas tasas de población de orígenes culturales diversos. Para ello, hemos optado por una metodología hibrida de investigación, en la que utilizaremos, de manera integrada, los paradigmas cuantitativo y cualitativo. En el primer caso se empleó el análisis descriptivo de dos cuestionarios dirigidos uno a estudiantes (Anexo 2), y otro al profesorado del centro (Anexo 3), usando para ello el programa SPSS V.22. En el segundo caso, se realizó el análisis de contenido utilizando el programa Aquad V.7, aplicando un sistema de categorías a las entrevistas realizadas al profesorado y estudiantes del centro (Anexo 4) y a los documentos del mismo (Anexo I). Partimos de una perspectiva etnográfica, ya que pretendemos describir y conocer cómo se manifiesta la competencia intercultural, en los estudiantes desde las perspectivas de sus protagonistas y la visión de los docentes del I.E.S. Miguel de Cervantes. También adoptamos una visión investigadora propia de la fenomenología, que nos permita representar las opiniones e interpretaciones de los significados que los protagonistas hacen sobre la vivencia en dicho centro escolar en relación con la competencia intercultural. A través de la integración de ambas perspectivas abarcaremos de forma más completa tanto la descripción como el conocimiento y entendimiento de la realidad estudiada.

\subsection{Técnicas e instrumentos de recogida y análisis de datos}

Para indagar en la temática objeto de estudio se procedió a recoger los datos a través de diversas técnicas como el análisis documental, la encuesta y la entrevista. Los distintos instrumentos utilizados fueron creados ad hoc, al igual que el sistema de categorías empleado en el análisis de contenido de las entrevistas atendiendo a las características y particularidades concretas del 
fenómeno estudiado, y al perfil de los informantes. La tabla 1, resume las distintas técnicas e instrumentos de recogida y análisis de los datos empleados para la realización de nuestro estudio.

Tabla 1 (Continuación)

Resumen técnicas e instrumentos de recogida y análisis de datos.

\begin{tabular}{lll}
\hline $\begin{array}{l}\text { Técnica de } \\
\text { recogida }\end{array}$ & Instrumento de recogida & Técnica de análisis \\
\hline $\begin{array}{l}\text { Análisis } \\
\text { documental }\end{array}$ & Inventario & $\begin{array}{l}\text { Análisis de contenido. Estudio } \\
\text { descriptivo } f \text { y } \% \text {. AQUAD V.7 }\end{array}$ \\
Encuesta & $\begin{array}{l}\text { Cuestionario estudiantes (Anexo A.1) } \\
\text { Cuestionario profesorado (Anexo A.2) }\end{array}$ & $\begin{array}{l}\text { Estudio descriptivo y correlacional } f \\
\mathrm{y} \% \text {. SPSS V.22. }\end{array}$ \\
Entrevistas & $\begin{array}{l}\text { Guión de entrevista para profesorado y } \\
\text { estudiantes de } 3^{\circ} \mathrm{y} 4^{\circ} \text { ESO (Anexo B) }\end{array}$ & $\begin{array}{l}\text { Análisis de contenido. Estudio } \\
\text { descriptivo } f \text { y } \% \text {. AQUAD V.7 }\end{array}$ \\
\hline
\end{tabular}

Para comenzar, necesitamos valorar el rol de la propia institución en el tratamiento de la cuestión intercultural, es decir, conocer cómo se trabaja la diversidad, la multiculturalidad e interculturalidad, así como las estrategias educativas que se llevan a cabo en el proceso de integración del alumnado inmigrante. Para ello, partimos del análisis documental de los documentos oficiales del centro, concretamente del Plan Educativo de Centro, usando para ello un inventario que nos permitió organizar la información y aquellos datos de interés.

También se administraron dos tipos de cuestionario. Uno dirigido a estudiantes (23 ítems) y otro a docentes (ítems), en los que se pedía el grado de acuerdo con una serie de afirmaciones usando para ello una escala tipo Likert, de 1 (Totalmente desacuerdo) a 5 (Totalmente de acuerdo). Se recogieron un total de 85 cuestionarios, 9 de profesores y 76 de los estudiantes de $3^{\circ}$ y $4^{\circ}$ de la E.S.O. del I.E.S. Miguel de Cervantes de Sevilla.

Por último, se realizaron 15 entrevistas en profundidad, abierta y semiestructurado, con un guion distinto en función del perfil del entrevistado, esto es profesor o estudiante. De este modo, se realizaron 4 entrevistas a profesores y 11 a estudiantes.

La tabla 2, recoge el sistema de categorías usado para análisis de contenido cualitativo de los datos obtenidos de las entrevistas y del inventario, que a su vez sirvieron para el diseño de los distintos instrumentos.

Tabla 2

Sistema de categorías para el análisis de contenido cualitativo. Dimensión Competencia intercultural

\begin{tabular}{|c|c|c|}
\hline Categoría & Subcategoría & Descripción \\
\hline \multirow{5}{*}{$\begin{array}{l}\text { Actitudes positivas } \\
\text { ante la diversidad } \\
\text { cultural }\end{array}$} & $\begin{array}{l}\text { Tengo amigos de otras culturas o } \\
\text { creencias }\end{array}$ & $\begin{array}{l}\text { Establecer relaciones de afecto, simpatía y } \\
\text { confianza. }\end{array}$ \\
\hline & $\begin{array}{l}\text { Busco el trato con personas de mi } \\
\text { misma cultura u otras culturas o } \\
\text { creencias }\end{array}$ & $\begin{array}{l}\text { Hace referencia a la tendencia de relacionarnos } \\
\text { con personas de nuestra misma cultura u de otras } \\
\text { culturas o creencias. }\end{array}$ \\
\hline & Tolerancia & $\begin{array}{l}\text { Actitud de respeto hacia las opiniones, ideas o } \\
\text { actitudes de los demás aunque no se esté de } \\
\text { acuerdo }\end{array}$ \\
\hline & $\begin{array}{l}\text { Relaciones positivas o negativas de } \\
\text { las personas de otras culturas o } \\
\text { creencias }\end{array}$ & $\begin{array}{l}\text { Establecer relaciones que resulten beneficiosas o } \\
\text { relaciones que producen daño o prejuicio }\end{array}$ \\
\hline & $\begin{array}{l}\text { Experiencias con personas de otras } \\
\text { culturas o creencias }\end{array}$ & $\begin{array}{l}\text { Compartir vivencias con personas de otras } \\
\text { culturas o creencias }\end{array}$ \\
\hline \multirow{2}{*}{$\begin{array}{l}\text { Habilidades } \\
\text { comunicativas }\end{array}$} & Conocer otras lenguas & $\begin{array}{l}\text { Dominar el uso funcional de al menos una lengua } \\
\text { extranjera. }\end{array}$ \\
\hline & Asertividad & $\begin{array}{l}\text { Capacidad para expresar y defender nuestras } \\
\text { ideas y derechos respetando a los demás. }\end{array}$ \\
\hline
\end{tabular}


Tabla 2

Sistema de categorías para el análisis de contenido cualitativo. Dimensión Competencia intercultural

\begin{tabular}{lll}
\hline Categoría & (Continuacíib)categoría & Descripción \\
\hline & Empatía & $\begin{array}{l}\text { Capacidad de comprender los sentimientos del } \\
\text { otro }\end{array}$ \\
\hline & $\begin{array}{l}\text { Considerar a la realidad permeable } \\
\text { a otras culturas }\end{array}$ & $\begin{array}{l}\text { Hace referencia a la capacidad de comprender y } \\
\text { aceptar otras culturas o creencias. }\end{array}$ \\
\cline { 2 - 3 } $\begin{array}{l}\text { Capacidad de } \\
\text { reflexión sobre la } \\
\text { propia cultura }\end{array}$ & \begin{tabular}{l} 
Etnocentrismo \\
\cline { 2 - 3 }
\end{tabular} & $\begin{array}{l}\text { Actitud con la que se analiza el mundo de } \\
\text { acuerdo a los parámetros de la cultura propia }\end{array}$ \\
\cline { 2 - 3 } & Relativismo cultural & $\begin{array}{l}\text { Considerar que todas las creencias, costumbres y } \\
\text { ética son relativas al individuo en su contexto } \\
\text { social }\end{array}$ \\
\end{tabular}

\section{Resultados}

Como recordaremos, la competencia intercultural la definimos como un conjunto de habilidades que nos permiten comunicarnos de manera afectiva en contextos donde interactúan distintas culturas y creencias. Esto supone también la adquisición de conocimientos sobre las costumbres y creencias de los otros, convirtiéndose así en una capacidad que nos permite reflexionar sobre la propia cultura y la de los demás, además de facilitar la comunicación con el otro. En este sentido, podemos decir que en la mayoría de ítems del cuestionario dirigido a los estudiantes (Anexo A.1) estos se muestran "muy de acuerdo" o "de acuerdo" con las afirmaciones planteadas. Así los ítems $1,2,3,4.5,6,11,19,26,33,35,36,37,38,39,40,41,42,43$ y 44, son puntuados con más de 50\% en sentido positivo sobre la persona inmigrante. De esto podemos deducir que el alumnado encuestado del I.E.S. Miguel de Cervantes presenta un grado de competencia intercultural bastante positivo.

Asimismo, el total de los 135 códigos registrados tras el análisis de contenido cualitativo de las entrevistas de los estudiantes, donde encontramos una puntuación más alta es en la categoría Actitudes positivas ante la diversidad, en la que dos de sus subcategorías Competencia intercultural Tolerancia (CIT) y Relaciones positivas o negativas de las personas de otras culturas o creencias (CORPN) comparten el mismo porcentaje de respuesta $(8,71 \%)$. Por otro lado, en esta dimensión encontramos dos códigos que no se encuentran representados en ninguno de los discursos emitidos por los estudiantes, estos son el de Competencia Intercultural Conocer otras lenguas (CILC) y Competencia Intercultural Asertividad (CIA), ambas subcategorías pertenecen a la categoría Actitudes positivas ante la diversidad cultural. Podemos decir que los códigos que más se repiten son aquellos relacionados con la tolerancia y las relaciones tanto positivas como negativas que establecen con las personas de otras culturas y creencias.

Los resultados de los cuestionarios dirigidos al profesorado del centro (Anexo A.2), en relación con la competencia intercultural de su alumnado, encontramos que al igual que sus estudiantes el profesorado se muestra muy de acuerdo o de acuerdo en la mayoría de la afirmaciones que componen la dimensión competencia intercultural, ya que en los ítems 1, 2, 3, 4, 5, 6, 26, 28, 37, 38, 39, 40, 41, 42, 43, 44 realizan puntuaciones superiores al 50\%. De este modo parece que el profesorado considera que sus alumnos son competentes desde una perspectiva intercultural, por lo que sabrían reconocer los distintos tipos de prejuicios, estereotipos y racismos.

El análisis de las entrevistas al profesorado revela que en la dimensión "Competencia Intercultural", hay una categoría Actitudes positivas ante la diversidad, en la que dos de sus subcategorías Competencia intercultural Tolerancia (CIT) y Relaciones positivas o negativas de las personas de otras culturas o creencias (CORPN) comparten el mismo porcentaje (12,70\%), representado así los códigos más usados en esta dimensión. Por otro lado, hay otros códigos que no se encuentran representados en ninguno de los discursos analizados. Son los pertenecientes a las categorías de Habilidades sociales como Competencia Intercultural Conocer otras lenguas (CILC) y Competencia Intercultural Asertividad (CIA). Podemos decir, que en las entrevistas al profesorado las subcategorías Competencia intercultural Tolerancia y Relaciones positivas o negativas de las personas de otras culturas o creencias son la que más se 
repiten al igual que en las entrevistas realizadas a los estudiantes.

A continuación, presentaremos los resultados de nuestro estudio en relación con la Competencia intercultural en el I.E.S. Miguel de Cervantes, diferenciando entre las visiones de docentes y discentes.

\subsection{Categoria "Actitudes positivas ante la diversidad cultural"}

Dentro de la categoría Actitudes positivas ante la diversidad cultural del estudiante, mostramos los ítems que aparecen en los cuestionarios realizados por el alumnado y el profesorado de I.E.S. Miguel de Cervantes, referidas a esta categoría, las cuales vamos analizar y complementar con fragmentos extraídos de las entrevistas realizadas a ambas muestras. En primer lugar, mostraremos todos los datos obtenidos del grupo de estudiantes, y en segundo lugar, los testimonios de los docentes.

Con respecto a los resultados obtenidos de los instrumentos realizados por el alumnado, en primer lugar presentamos los datos del cuestionario. Esta categoría está compuesta por 12 ítems, de los cuales podemos deducir que más del $75 \%$ de los estudiantes afirma estar muy de acuerdo o de acuerdo con la afirmación "Reconocer los derechos de todas las personas a vivir y a trabajar en cualquier país". También se muestra muy de acuerdo o de acuerdo el 77,5\% de los estudiantes con la afirmación "En clase se fomenta la tolerancia". Con respecto al ítem "En clase se fomenta el respeto hacia otras culturas y religiones", el 77.3\% de los mismos se encuentra muy de acuerdo o de acuerdo con dicha afirmación. Sin embargo, en el ítem "Pienso que España es un país tolerante" el $52,6 \%$ de los estudiantes opina sentir indiferencia o se muestra muy en desacuerdo o en desacuerdo. Podemos concluir que los estudiantes se perciben a sí mismos como personas tolerantes, y que son capaces de tener actitudes de respeto hacia las opiniones, ideas o actitudes de los demás aunque no se esté de acuerdo con ellas, sin embargo, no consideran que su país sea tolerante con las personas de otras nacionalidades.

E: En la barriada del Cerezo hay... que está muy próxima al centro hay una mezquita ¿Qué te parece que las personas que practican la religión musulmana tengan su propio templo?

A: En verdad me parece bien porque tienen su cultura aqui al lado de donde viven y... en verdad me parece bien.

(Entrevista E3. Líneas 14-17)

En el ítem "Tengo simpatía por..." cuando se refiere a las personas de origen africano, chino, sudamericano, rumano o árabe, más de un $50 \%$ de los estudiantes encuestados afirman estar muy de acuerdo o de acuerdo con estas afirmaciones. Sin embargo, cuando se refiere a las personas de origen gitano más del $50 \%$ afirma sentirse indiferente, muy en desacuerdo o en desacuerdo.

E: ¿Te sientes inseguro cuando tienes cerca personas de origen gitano?

A: Si.

(Entrevista E6. Líneas 24-25)

A la hora de colaborar en grupo con compañeros de otras culturas y creencias más del $80 \%$ está muy de acuerdo o de acuerdo con esta afirmación. Podemos decir que los estudiantes buscan relacionarse con personas de cualquier cultura y creencia, pero que tienden a no establecer relaciones con personas de cultura gitana.

\section{E: ¿Tienes amigos gitanos, negros, rumanos...?}

A: Si.

(Entrevista E11. Líneas 32-33)

Con respecto al ítem "No me importaría que alguien de mi entorno familiar estableciera una relación afectiva con una persona de otra cultura y creencia”, un 56.6\% está de acuerdo con esta afirmación. Con respecto a los ítems "Mis padres pertenecen al AMPA de mi instituto", "Voy a los cumpleaños de mis amigos inmigrantes", "En mi comunidad tengo vecinos de origen inmigrante” y 
"En clase se fomentan las relaciones interculturales" podemos decir que los estudiantes afirman con más del $50 \%$ estar de acuerdo con todas estas afirmaciones, mientras que el $64,5 \%$ se muestra muy en desacuerdo con el ítem "Mis padres se relacionan con otros padres de compañeros inmigrantes". Podemos decir, en general, que los alumnos dicen relacionarse de forma positiva con personas de otras culturas o creencias por lo que sus experiencias con personas en este sentido son también positivas. Sin embargo, el alumnado no considera que sus padres sí mantengan relaciones de este tipo con los padres de sus compañeros de origen inmigrante. Este hecho puede deberse a una cuestión generacional y educacional al no haber sido educados en una sociedad abierta a la multiculturalidad, en una España en la que la inmigración proveniente del exterior era un hecho considerado extraordinario.

\section{a) Profesorado}

En cuanto a los resultados de los cuestionarios del profesorado en relación a esta categoría, podemos decir con respecto al ítem "Mis estudiantes reconocen el derecho de todas las personas a vivir y a trabajar en cualquier país" que el $75 \%$ del profesorado está muy de acuerdo con esta afirmación. En los ítems "En clase se fomenta la tolerancia” y "En clase se fomenta el respeto hacia otras culturas, religiones, etc." más del 50\% del profesorado está de acuerdo o muy de acuerdo con esta afirmación. Sin embargo, en la afirmación "Mis estudiantes piensan que España es un país tolerante" más del 50\% del profesorado se muestra indiferente, mostrándose muy en desacuerdo o en desacuerdo con esta afirmación. Podemos decir que al igual que los estudiantes el profesorado piensa que su alumnado es tolerante.

En el ítem "Tengo simpatía por..." cuando se refiere a las personas de origen africano, chino, sudamericano, rumano o árabe más de un $50 \%$ del profesorado afirma estar muy de acuerdo o de acuerdo con estas afirmaciones. Sin embargo, cuando se refiere a las personas de origen gitano más del $50 \%$ afirma sentirse indiferente, muy en desacuerdo o en desacuerdo. A la hora de agrupar al alumnado de forma inclusiva, más del $80 \%$ está muy de acuerdo o de acuerdo con esta afirmación. Podemos decir que el profesorado percibe que sus estudiantes se relacionan bien con personas de cualquier cultura y creencia, pero que tienden a no establecer relaciones con personas de cultura gitana.
E: ¿Y las actitudes de los alumnos de otras culturas o creencias con los autóctonos?
P: También veo que es correcta pero quizás con más... con más lejanía, con un cierto distancia como "viéndolas venir" sería, a ver qué pasa a ver cómo me reciben aquí eso es lo que en en... pero no es tampoco negativa de principio sino una especie de "vamos a ir poquito a poco no vaya a ser que no me quieran del todo admitiv", eso es lo que yo... me parece a mí.

(Entrevista P1. Líneas 16-25)

Con respecto al ítem "A mis estudiantes no les importaría que alguien de su entorno familiar estableciera una relación afectiva con una persona de otra cultura y creencia "más de un 50,0 \% está de acuerdo con esta afirmación

Al ser preguntados por si "Los padres de mis alumnos se relacionan con otros padres de compañeros inmigrantes", "Mis estudiantes asisten a los cumpleaños de sus compañeros inmigrantes", "Mis estudiantes tienen vecinos de origen inmigrante" y "En clase se fomentan las relaciones interculturales" podemos decir que los profesores afirman en más del $50 \%$ de las ocasiones estar de acuerdo con todas estas afirmaciones, mientras que el 64,5\% se muestra muy en desacuerdo con el ítem "Los padres de mis alumnos se relacionan con otros padres de compañeros inmigrantes".

En general, el profesorado del centro en el que realizamos nuestro estudio considera que los estudiantes se relacionan de forma positiva con personas de otras culturas o creencias, por lo que sus experiencias en este sentido son positivas. Sin embargo, el profesorado al igual que el alumnado no considera que los padres sí mantengan relaciones de este tipo con los padres de los compañeros de sus hijos. 


\subsection{Categoría "Habilidades comunicativas"}

En cuanto a los análisis obtenidos en la categoría Habilidades comunicativas, mostramos a continuación los porcentajes obtenidos en el conjunto de ítems analizados en relación a esta categoría tanto de los estudiantes como del profesorado.

\section{a) Estudiantes}

En primer lugar, mostramos los resultados obtenidos en los cuestionarios realizados a los estudiantes. El ítem que hace referencia a si el alumnado reconoce las nacionalidades y lenguas de otras culturas, más del 50\% de los encuestados se muestran muy de acuerdo o de acuerdo con esta afirmación. Los ítems "Gracias a ellos conocemos otras culturas y lenguas", "En clase se utiliza un lenguaje no discriminatorio" y "En clase aprendemos a comunicarnos de forma intercultural" los encuestados puntúan con más del 50\% estas afirmaciones. Esto significa que el alumnado posee habilidades comunicativas, y que también muestran empatía, como podemos ver en los resultados de la afirmación "Soy consciente de las circunstancias que frecuentemente obligan a las personas a emigrar" en la que más del $80 \%$ se muestra muy de acuerdo o de acuerdo con esta afirmación. Un ejemplo de esta visión empática del alumnado, la encontramos en afirmaciones tales como:

Mientras que sean buenas personas y nos puedan aportar cosas buenas no nos tiene por quitar el trabajo

(Entrevista E6. Líneas 11-13)

\section{b) Profesorado}

En relación a los resultados de los cuestionarios del profesorado en referencia a esta categoría, deducimos que más del $60 \%$ del profesorado piensa que sus estudiantes reconocen las nacionalidades y lenguas de otras culturas. En los ítems "Gracias a ellos conocemos otras culturas y lenguas", "En clase se utiliza un lenguaje no discriminatorio" y "En clase aprendemos a comunicarnos de forma intercultural" los encuestados puntúan con más del $50 \%$ cada afirmación. Con ello podemos decir que el profesorado piensa que su alumnado posee habilidades comunicativas, y que también muestran empatía, como podemos ver en los resultados de la afirmación "Soy consciente de las circunstancias que frecuentemente obligan a las personas a emigrar" en la que más del $80 \%$ se muestra muy de acuerdo o de acuerdo con esta afirmación.

En cuanto a los intereses de los alumnos por conocer el lenguaje o tradiciones de sus compañeros de otras culturas o creencias opinan:

P: No mucho, no mucho, si que se hacen actividades también con eso, a veces se ha becho por ejemplo que cada uno traiga una comida de su país y tal, le resulta curioso pero tampoco... tú sabes que los adolescentes tampoco tienen mucha curiosidad, pero casi por nada pero bueno, tampoco es que muestren un interés loco.

(Entrevista P3. Líneas 99-103)

\subsection{Categoria "Capacidad de reflexión sobre la propia cultura"}

Con esta categoría "Capacidad de reflexión sobre la propia cultura" finalizamos la dimensión Competencia Intercultural. A continuación, presentamos los resultados obtenidos de los cuestionarios realizados tanto al alumnado como al profesorado.

\section{a) Estudiantes}

En relación a la categoría "Capacidad de reflexión sobre la propia cultura" los estudiantes se muestran en referencia a los ítems "Conozco las distintas religiones", "Conozco el origen de los monumentos más importantes de mi ciudad como por ejemplo el de la Giralda" y "Muchos de nuestros alimentos viene de otros países", más del $80 \%$ de los estudiantes se encuentran muy de acuerdo o de acuerdo con esta afirmación. 
Podemos decir que los estudiantes comprenden y aceptan otras culturas y creencias. En el ítem "Las personas inmigrantes viven de la delincuencia y de las drogas" el 73,2 \% del alumnado se muestra muy en desacuerdo con esta afirmación, por lo que podemos decir que los encuestados no muestran actitudes etnocentristas. Por otro lado, y refiriéndonos al ítem "Con los inmigrantes aprendemos muchas cosas" más del $80 \%$ del alumnado se manifiesta muy de acuerdo o de acuerdo con esta afirmación.

\section{b) Profesorado}

El profesorado se muestra en referencia a los ítems "Mis estudiantes conocen las distintas religiones", "Mis estudiantes conocen el origen de los monumentos más importantes de mi ciudad como, por ejemplo, el de la Giralda." y "Mis estudiantes conocen que muchos de nuestros alimentos viene de otros países" más del 50\% dicen estar muy de acuerdo o de acuerdo con esta afirmación. Podemos decir que el profesorado considera que los estudiantes comprenden y aceptan otras culturas y creencias.

En el ítem "Mis estudiantes creen que las personas inmigrantes viven de la delincuencia y de las drogas" el 73,7\% del profesorado se muestra muy en desacuerdo con esta afirmación, por lo que podemos decir que los encuestados piensan que sus estudiantes no muestran actitudes etnocentristas. Por otro lado, y refiriéndonos al ítem "Mis estudiantes piensan que con los inmigrantes aprendemos muchas cosas" y "En clase conocemos la cultura de otros países", más del $80 \%$ del profesorado se manifiesta muy de acuerdo o de acuerdo con esta afirmación, con ello deducimos que los profesores/as piensan que sus estudiantes consideran positivamente otras culturas además de la suya.

\section{E: ¿Ha contribuido a que los alumnos valoren como positivo el pluralismo cultural? \\ P: Intento que sí, intento pensar que si o me gustaría pensar que si, que... que lo valoren de esa... esa manera que... que nos enriquezcan a todos el ver distintas formas de ver la vida, de ver la cultura, de ver algo que pasa, quiero pensar que sí.}

(Entrevista P2. Líneas 117-122)

\section{Discusión y conclusiones}

\subsection{Jóvenes frente al espejo de la interculturalidad}

En nuestro trabajo pretendíamos estudiar a través de varios ítems, distintos aspectos tales como las actitudes positivas ante la diversidad, las habilidades comunicativas y la capacidad de reflexión sobre la cultura, elemento definitorios de la Competencia Intercultural. En los cuestionarios, con respecto a las actitudes positivas ante la diversidad, encontramos que los estudiantes se perciben a ellos mismos como tolerantes, mostrando así actitudes de respeto hacia las opiniones, ideas o actitudes de los demás. Por otro lado, los estudiantes manifiestan tener amigos/as de otras culturas, es decir que establecen relaciones de afecto y confianza con personas de diferentes orígenes, aunque también muestran una tendencia a relacionarse más con las personas de su misma cultura. El alumnado también suele establecer relaciones más positivas que negativas con personas de otras culturas y creencias, y pese a que valoran de forma positiva las vivencias que comparten con otras culturas, expresan ciertas dificultades para relacionarse con ciertas culturas, como la gitana o la rumana.

Con respecto a las habilidades comunicativas, el alumnado en los cuestionarios expresa saber comunicarse de forma intercultural y reconocer las distintas lenguas que hablan las personas de otras culturas. También manifiestan tener capacidad para empatizar y saber comunicarse de manera asertiva. Sin embargo, en sus testimonios podemos observar que a la hora de resolver conflictos utilizan el origen cultural o étnico como un recurso para el ataque, lo cual pone en duda la capacidad asertiva que dicen tener.

Por último, sobre la capacidad de reflexión de la propia cultura podemos decir que los 
estudiantes en los cuestionarios dicen aceptar la realidad permeable de otras culturas, ya que consideran que gracias a la inmigración conocemos otras realidades y creencias. Aunque al mismo tiempo interpretan en muchas ocasiones la realidad según los parámetros de su propia cultura.

El profesorado, a su vez, también percibe que sus estudiantes tienen actitudes positivas hacia las personas de otras culturas. Así consideran que los alumnos y alumnas se muestran tolerantes, al tiempo que comparten la idea de que tienen la capacidad para establecer relaciones positivas con las personas de otras culturas y creencias, en general, con la salvedad de aquellos que provienen de la comunidad gitana, frente a los que muestran ciertas reticencias. En cualquier caso piensan que sus estudiantes se relacionan mayoritariamente de forma positiva, por lo que podemos entender que estos tienen experiencias agradables con las personas de otros perfiles culturales.

Sobre las habilidades comunicativas el profesorado considera que sus alumnos muestran empatía y son capaces de comunicarse de forma asertiva. Por último, el profesorado considera que sus alumnos son capaces de comprender y aceptar otras culturas y creencias, además creen que sus alumnos no muestran actitudes etnocentristas por lo tanto considerar la cultural relativa al individuo.

\subsection{Manchas en el espejo. Discrepancias encontradas}

Respecto a la veracidad de las repuestas obtenidas en los cuestionarios y en las entrevistas, encontramos ciertas discrepancias entre lo que expresan en los cuestionarios y en las entrevías, tanto por parte del alumnado como del profesorado pero siendo más contradictoras en el caso de los docentes. Esto puede deberse a que en las entrevistas tanto profesores como estudiantes le dan ciertos matices a las respuestas que no pueden ser aportadas en los cuestionarios.

Podemos decir, en general, que los estudiantes se perciben así mismos con capacidades interculturales. El profesorado, a su vez, no tiene la misma percepción sobre su alumnado, ya que considera que no siempre tienen actitudes de respeto hacia las opiniones, ideas o actitudes de los demás. También el profesorado reconoce que su alumnado muestra ciertas dificultades a la hora de relacionarse con ciertas culturas como la gitana. En relación a las habilidades comunicativas, deducimos que el profesorado comparte la opinión de sus estudiantes, pero no los considera muy asertivos ya que a la hora de los conflictos entre alumnos de diferentes culturas, los ataques que se realizan hacen referencia al origen. Sobre la capacidad de reflexión sobre la propia cultura, el profesorado piensa que sus estudiantes no comprenden ni aceptan del todo otras culturas, al igual que piensa que tampoco valoran los aprendizajes que nos proporcionan otras culturas.

\subsection{Es necesario seguir trabajando...}

De todo lo dicho, podemos deducir que el alumnado muestra cierto grado de adquisición de las capacidades relacionadas con la competencia intercultural pero, al mismo tiempo, estas conviven con actitudes prejuiciosas y estereotipadas hacia las personas de otras culturas y creencias. Para poder erradicar estas actitudes negativas se hace necesario favorecer y estimular la competencia intercultural de los estudiantes, tal y como dice la documentación oficial del propio centro:

"La Atención a la Diversidad debe estar orientada a que el alumnado alcance, en la medida de sus posibilidades, las competencias básicas (...) La estructura y el contenido de los distintos elementos curriculares han de tender a alcanzar las competencias básicas y tener en cuenta la diversidad que se aprecia en el aula"

(Inventario Líneas 2923-3044).

Dado que estamos en un entorno multicultural, deben enfrentarse a diario a multitud de situaciones en las que, tanto los estudiantes autóctonos como los provenientes de otras culturas y creencias, deben interactuar entre sí. Estas interacciones no solo se darán dentro del centro, lo cierto es que será en el mundo fuera de este, donde la mayoría de estas interacciones tendrán lugar, y es, por esta razón, por la que creemos que la competencia intercultural tendría que ser parte de 
esas competencias básicas de la ciudadanía, dejando así de ser una formación puntual. La sociedad necesita adultos capaces de convivir de forma democrática, siendo críticos, reflexivos y globales, capaces de compartir y respetar las distintas individualidades que enriquecen a la sociedad en su conjunto.

Esto se podría lograr si los centros elaboraran un auténtico currículum en el que la Educación Intercultural estuviera aún más presente. Hemos observado a través de los resultados recogidos que, los miembros de la comunidad educativa del I.E.S. Miguel de Cervantes, trabajan aspectos interculturales y se preocupan de la diversidad, y además de ser conscientes de que se enriquecen con ella, pero también hemos encontrado que se trabaja de manera puntual y en muchas ocasiones con agentes externos, más que desde los profesionales que forman parte del personal del centro. Sería aconsejable, en orden a conseguir una mayor significatividad para los profesionales que lo integran, que el profesorado sintiera la necesidad de formarse en interculturalidad para poder así elaborar e impartir sus asignaturas de manera integradora, haciendo sentir a todos sus estudiantes representados en la comunidad educativa a la cual pertenecen. Esto supone una tarea compleja, debido a otros factores que aquí no llegamos a analizar pero que nos han cuestionado y planteado posibles vías de trabajo e investigación futuras.

\subsection{Nuestra propuesta de desarrollo de la interculturalidad}

Nuestro objetivo fundamental sería desarrollar la competencia intercultural de estudiantes y profesores, de manera integrada en la vida del I.E.S. Miguel de Cervantes de Sevilla, así como actualizar la formación intercultural de estos últimos. A lo largo de nuestro trabajo hemos constatado la existencia de ciertos aspectos a considerar y que reflejamos en el DAFO que aparece a continuación.

\begin{tabular}{|l|l|}
\hline Debilidades & Amenazas \\
- Escasa formación sobre interculturalidad & - Aspectos sociales (Absentismo, fracaso \\
del profesorado. & escolar, Falta de colaboración de la \\
- Ausencia de un Plan Intercultural. & familia...). \\
- Falta de un currículum intercultural. & - Incomprensión de la inmigración. \\
- Falta de continuidad de las actuaciones & - Racismos \\
interculturales. & - Prejuicios \\
\hline Fortalezas & - Estereotipos \\
- Presencia de educadora social. & Oportunidades \\
- Presencia de mediadores y colaboradores & - Espacio multicultural \\
interculturales. & - Aportaciones enriquecedoras \\
- Actividades interculturales & - Acercamiento a diferentes culturas \\
\hline
\end{tabular}

Las siguientes líneas de actuación, que podrían formar parte también de la propuesta formativa de centros que quieran desarrollar su labor en este sentido, y que creemos prioritarias serían:

- Dirigida a los estudiantes:

a) Desarrollo de la competencia intercultural en todos y cada uno de sus distintos aspectos.

- Dirigida a los profesores:

a) Actualización en la atención a la diversidad intercultural.

b) Desarrollo de la competencia intercultural.

Que podemos materializar en la propuesta que presentamos ahora en las tablas 3 y 4 . Se trata de un programa intercultural en el que se necesita un pleno compromiso de toda la comunidad educativa. 
Tabla 3

Propuesta de intervención dirigida a los Estudiantes

\begin{tabular}{|c|c|c|}
\hline Líneas de actuación & Objetivos & Contenido \\
\hline $\begin{array}{l}\text { Conceptos básicos e } \\
\text { intercambio de } \\
\text { experiencias }\end{array}$ & $\begin{array}{l}\text { - Favorecer las actitudes positivas } \\
\text { respecto a la diversidad cultural } \\
\text { - Aplicar conocimientos acerca de las } \\
\text { costumbres y creencias del otro } \\
\text { (Empatía). }\end{array}$ & $\begin{array}{ll}\text { - } & \text { La multiculturalidad. } \\
\text { - } & \text { Tolerancia } \\
\text { - } & \text { Etnocentrismo y relativismo } \\
\text { cultural. } \\
\text { - Prejuicios, estereotipos y racismos. } \\
\text { - Charlas de personas de distintas } \\
\text { procedencia }\end{array}$ \\
\hline Conocer otras lenguas & $\begin{array}{l}\text { - Desarrollar: } \\
\text { - las habilidades comunicativas. } \\
\text { - la capacidad de reflexión } \\
\text { sobre las distintas culturas }\end{array}$ & $\begin{array}{l}\text { - Asertividad. } \\
\text { - Empatía. } \\
\text { - } \\
\text { - } \text { Senguaje verbal y no verbal } \\
\text { - Cortos en diferentes idiomas con } \\
\text { temática cultural e intercultural }\end{array}$ \\
\hline Salidas Culturales & $\begin{array}{l}\text { - Conocer las costumbres de otras } \\
\text { culturas } \\
\text { - Reflexionar sobre la realidad } \\
\text { permeable de otras culturas }\end{array}$ & $\begin{array}{l}\text { - Visitas temáticas. } \\
\text { - Convivencias }\end{array}$ \\
\hline
\end{tabular}

Tabla 4

Propuesta de intervención dirigida a Profesores

\begin{tabular}{|c|c|c|}
\hline Líneas de actuación & Objetivos & Contenido \\
\hline $\begin{array}{l}\text { Conocimientos básicos } \\
\text { e Intercambio de } \\
\text { experiencias }\end{array}$ & $\begin{array}{l}\text { - Favorecer las actitudes positivas } \\
\text { respecto a la diversidad cultural } \\
\text { - Aplicar conocimientos acerca de } \\
\text { las costumbres y creencias del otro } \\
\text { (Empatía). }\end{array}$ & $\begin{array}{l}\text { - Derechos y libertades. } \\
\text { - Xenofobias y racismos. } \\
\text { - Prejuicios y estereotipos. } \\
\text { - Asertividad. } \\
\text { - Empatía. } \\
\text { - Lenguaje verbal y no verbal. } \\
\text { - Sensibilidad intercultural. } \\
\text { - La multiculturalidad. } \\
\text { - Tolerancia } \\
\text { - Etnocentrismo y relativismo cultural. }\end{array}$ \\
\hline Conocer otras lenguas & $\begin{array}{l}\text { - Desarrollar } \\
\text { - habilidades sociales. } \\
\text { - la capacidad de reflexión } \\
\\
\text { sobre las culturas. }\end{array}$ & $\begin{array}{l}\text { - Asertividad. } \\
\text { - Empatía. } \\
\text { - Lenguaje verbal y no verbal. } \\
\text { - Sensibilidad intercultural. } \\
\text { - Cortos en diferentes idiomas con } \\
\text { temática cultural e intercultural } \\
\text { - Charlas de personas de distintas } \\
\text { procedencia }\end{array}$ \\
\hline $\begin{array}{l}\text { Actualización en la } \\
\text { atención a la diversidad } \\
\text { intercultural }\end{array}$ & $\begin{array}{l}\text { - Conocer conceptos relacionados } \\
\text { con la educación integradora, } \\
\text { comprensiva, inclusiva. } \\
\text { - Desarrollar estrategias que: } \\
\text { - atiendan la diversidad } \\
\text { intercultural desde el } \\
\text { currículum. } \\
\text { - metodológicas interculturales } \\
\text { - Aplicar técnicas y estrategias para la } \\
\text { identificación de necesidades } \\
\text { culturales y sociales. }\end{array}$ & $\begin{array}{l}\text { - Conceptualización y evolución de la } \\
\text { Atención a la Diversidad: } \\
\text { normalización, integración, educación } \\
\text { comprensiva e inclusión escolar. } \\
\text { - La Atención a la Diversidad desde el } \\
\text { currículum. } \\
\text { - El apoyo colaborativo entre profesores. } \\
\text { - La organización del aula: técnicas y } \\
\text { estrategias } \\
\text { - La identificación y valoración de las } \\
\text { necesidades culturales y sociales. } \\
\text { - Estrategias específicas de intervención } \\
\text { intercultural en Educación secundaria }\end{array}$ \\
\hline
\end{tabular}

Este programa intercultural puede ser aplicado de muy diversas formas, las distintas necesidades detectadas aún no están por cubrir, por ello pretendemos trabajar para favorecer el desarrollo de la 
competencia intercultural y la formación del profesorado en estos aspectos para que esta competencia sea una herramienta no sólo de integración sino también de creación de verdaderos espacios educativos interculturales.

\section{Anexo A. Cuestionario sobre los prejuicios y estereotipos hacia los inmigrantes o hacia otras personas de distinta cultura o religión}

\section{Cuestionario para estudiantes}

Con el siguiente cuestionario se pretende conocer la opinión de los estudiantes de Secundaria sobre los inmigrantes y sobre otras personas con distinta cultura o religión, también se recogerá sus opiniones sobre la formación del profesorado. La información proporcionada será usada con fines estadísticos en un proyecto de investigación para la Universidad de Sevilla y será de carácter confidencial. Es muy importante que contestes el cuestionario completo y con honestidad. Agradecemos su cooperación.

EDAD:

GÉNERO:
CURSO:

NACIONALIDAD:

Marque con una X la alternativa que considere más correcta:

\begin{tabular}{|c|c|c|c|c|c|}
\hline \multicolumn{6}{|l|}{ 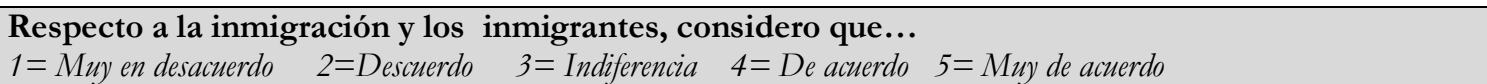 } \\
\hline $\begin{array}{l}\text { 1. Reconozco las nacionalidades y las distintas lenguas oficiales que hablan las } \\
\text { personas inmigrantes. }\end{array}$ & 1 & 2 & 3 & 4 & 5 \\
\hline 2. Reconozco el derecho de todas las personas a vivir y a trabajar en cualquier país. & 1 & 2 & 3 & 4 & 5 \\
\hline $\begin{array}{l}\text { 3. Soy consciente de las circunstancias que frecuentemente obligan a las personas a } \\
\text { emigrar. }\end{array}$ & 1 & 2 & 3 & 4 & 5 \\
\hline 4. Conozco las distintas religiones. & 1 & 2 & 3 & 4 & 5 \\
\hline $\begin{array}{l}\text { 5. Conozco el origen de los monumentos más importantes de mi ciudad como por } \\
\text { ejemplo el de la giralda. }\end{array}$ & 1 & 2 & 3 & 4 & 5 \\
\hline 6. Muchos de nuestros alimentos viene de otros países. & 1 & 2 & 3 & 4 & 5 \\
\hline 7. Los inmigrantes contribuyen a que en España se viva mejor & 1 & 2 & 3 & 4 & 5 \\
\hline 8. Los inmigrantes nos están invadiendo & 1 & 2 & 3 & 4 & 5 \\
\hline 9. Las personas inmigrantes son amables & 1 & 2 & 3 & 4 & 5 \\
\hline 10. Reciben más ayuda que los de aquí & 1 & 2 & 3 & 4 & 5 \\
\hline 11. Con los inmigrantes aprendemos muchas cosas & 1 & 2 & 3 & 4 & 5 \\
\hline 12. Las personas inmigrantes viven de la delincuencia y de las drogas & 1 & 2 & 3 & 4 & 5 \\
\hline 13. Las personas inmigrantes son trabajadoras & 1 & 2 & 3 & 4 & 5 \\
\hline 14. Por culpa de los inmigrantes se perderá la cultura de España & 1 & 2 & 3 & 4 & 5 \\
\hline 15. Deben tener los mismos derechos que los demás & 1 & 2 & 3 & 4 & 5 \\
\hline 16. Los inmigrantes quieren imponer su religión & 1 & 2 & 3 & 4 & 5 \\
\hline 17. Las personas inmigrantes hacen las cosas bien & 1 & 2 & 3 & 4 & 5 \\
\hline 18. Los inmigrantes hacen que aumente la delincuencia & 1 & 2 & 3 & 4 & 5 \\
\hline 19. Gracia a ellos conocemos otras culturas y lenguas & 1 & 2 & 3 & 4 & 5 \\
\hline 20. Los inmigrantes traen enfermedades a España & 1 & 2 & 3 & 4 & 5 \\
\hline 21. Las personas inmigrantes son buena gente & 1 & 2 & 3 & 4 & 5 \\
\hline 22. Las personas inmigrantes saturan los servicios sociales & 1 & 2 & 3 & 4 & 5 \\
\hline 23. Hacen los trabajos que la gente de aquí no quiere hacer & 1 & 2 & 3 & 4 & 5 \\
\hline 24. Los inmigrantes son más machistas que los de aquí & 1 & 2 & 3 & 4 & 5 \\
\hline 25. Ayudan a mejorar la economía de España & 1 & 2 & 3 & 4 & 5 \\
\hline \multicolumn{6}{|l|}{ 26. Tengo simpatía por: } \\
\hline - Las personas africanas & 1 & 2 & 3 & 4 & 5 \\
\hline Las personas chinas & 1 & 2 & 3 & 4 & 5 \\
\hline Las personas rumanas & 1 & 2 & 3 & 4 & 5 \\
\hline - $\quad$ Las personas gitanas & 1 & 2 & 3 & 4 & 5 \\
\hline - $\quad$ Las personas sudamericanas & 1 & 2 & 3 & 4 & 5 \\
\hline - $\quad$ Las personas árabes & 1 & 2 & 3 & 4 & 5 \\
\hline
\end{tabular}




\begin{tabular}{|c|c|c|c|c|c|}
\hline \multicolumn{6}{|l|}{ 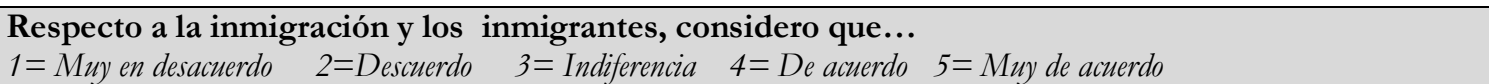 } \\
\hline 27. En España viven demasiadas personas inmigrantes. & 1 & 2 & 3 & 4 & 5 \\
\hline 28. Pienso que España es un país tolerante & 1 & 2 & 3 & 4 & 5 \\
\hline 29. Pienso que las personas de origen gitano si no la dan a la salida la dan a la entrada & 1 & 2 & 3 & 4 & 5 \\
\hline 30. Pienso que todos los árabes son musulmanes & 1 & 2 & 3 & 4 & 5 \\
\hline 31. Pienso que todos los musulmanes son islamistas radicales. & 1 & 2 & 3 & 4 & 5 \\
\hline 32. Pienso que todos los musulmanes son árabes. & 1 & 2 & 3 & 4 & 5 \\
\hline 33. Mis padres pertenecen al AMPA de mi instituto & 1 & 2 & 3 & 4 & 5 \\
\hline 34. Voy a los cumpleaños de mis amigos inmigrantes & 1 & 2 & 3 & 4 & 5 \\
\hline 35. Mis padres se relacionan con otros padres de compañeros inmigrantes & 1 & 2 & 3 & 4 & 5 \\
\hline 36. En mi comunidad tengo vecinos de origen inmigrante & 1 & 2 & 3 & 4 & 5 \\
\hline
\end{tabular}

\begin{tabular}{|c|c|c|c|c|c|}
\hline \multicolumn{6}{|l|}{ 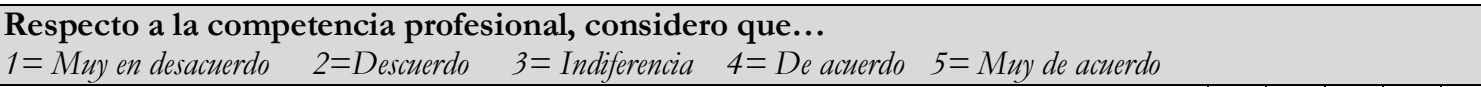 } \\
\hline 1. En clase conocemos la cultura de otros países & 1 & 2 & 3 & 4 & 5 \\
\hline En clase se utiliza un lenguaje no discriminatorio & 1 & 2 & 3 & 4 & 5 \\
\hline En clase se fomenta las relaciones interculturales & 1 & 2 & 3 & 4 & 5 \\
\hline En clase se fomenta la tolerancia & 1 & 2 & 3 & 4 & 5 \\
\hline En clase se fomenta el respeto hacia otras culturas, religiones, etc. & 1 & 2 & 3 & 4 & 5 \\
\hline 6. En clase aprendemos a comunicarnos de forma intercultural. & 1 & 2 & 3 & 4 & 5 \\
\hline 7. En los grupos de trabajo de clase colaboro con compañeros inmigrantes & 1 & 2 & 3 & 4 & 5 \\
\hline 8. En clase aprendemos a relacionarnos con personas de otras culturas & 1 & 2 & 3 & 4 & 5 \\
\hline 9. En clase aprendemos a resolver conflictos a través del dialogo. & 1 & 2 & 3 & 4 & 5 \\
\hline 10. Mis profesores saben relacionarse y comunicarse de forma habilidosa & 1 & 2 & 3 & 4 & 5 \\
\hline
\end{tabular}

\section{Cuestionario para profesorado}

Con el siguiente cuestionario se pretende conocer la opinión del profesorado de secundaria sobre lo que creen que sus alumnos piensan de los inmigrantes o de otras personas con distintas religión, cultura, etc., y también proporcionar información sobre su propia competencia profesional. La información proporcionada será usada con fines estadísticos en un proyecto de investigación para la Universidad de Sevilla y será de carácter confidencial. Es muy importante que contestes el cuestionario completo y con honestidad. Agradezco su cooperación.
EDAD:
GÉNERO:
CURSO:
PAÍS DE NACIMIENTO:

Marque con una X según tú opinión, ¿hasta qué punto son verdaderas estas frases?

\begin{tabular}{|c|c|c|c|c|c|}
\hline \multicolumn{6}{|l|}{$\begin{array}{l}\text { Respecto a que mis alumnos piensan sobre los inmigrantes o personas de otra } \\
\text { cultura o religión, considero que... } \\
\begin{array}{ll}1=\text { Muy en desacuerdo } \quad 2=\text { Descuerdo } \quad 3=\text { Indiferencia } \quad 4=\text { De acuerdo } \quad 5=\text { Muy de acuerdo }\end{array}\end{array}$} \\
\hline $\begin{array}{l}\text { 1. Mis alumnos reconocen las nacionalidades y las distintas lenguas oficiales que hablan } \\
\text { las personas inmigrantes }\end{array}$ & 1 & 2 & 3 & 4 & 5 \\
\hline $\begin{array}{l}\text { 2. Mis alumnos reconocen el derecho de todas las personas a vivir y a trabajar en } \\
\text { cualquier país }\end{array}$ & 1 & 2 & 3 & 4 & 5 \\
\hline $\begin{array}{l}\text { 3. Mis alumnos son conscientes de las circunstancias que frecuentemente obligan a las } \\
\text { personas a emigrar }\end{array}$ & 1 & 2 & 3 & 4 & 5 \\
\hline Mis alumnos conocen las distintas religiones. & 1 & 2 & 3 & 4 & 5 \\
\hline $\begin{array}{l}\text { Mis alumnos conocen el origen de los monumentos más importantes de mi ciudad } \\
\text { como por ejemplo: la giralda }\end{array}$ & 1 & 2 & 3 & 4 & 5 \\
\hline Mis alumnos conocen que muchos de nuestros alimentos viene de otros países & 1 & 2 & 3 & 4 & 5 \\
\hline $\begin{array}{l}\text { 7. Mis alumnos consideran que los inmigrantes contribuyen a que en España se viva } \\
\text { mejor }\end{array}$ & 1 & 2 & 3 & 4 & 5 \\
\hline Mis alumnos consideran que los inmigrantes nos están invadiendo & 1 & 2 & 3 & 4 & 5 \\
\hline
\end{tabular}


9. Mis alumnos consideran que las personas inmigrantes son amables

10. Mis alumnos consideran que los inmigrantes reciben más ayuda que los de aquí

11. Mis alumnos piensan que con los inmigrantes aprendemos muchas cosas

12. Mis alumnos creen que los inmigrantes hacen que aumente la delincuencia y las drogas

13. Mis alumnos consideran que las personas inmigrantes son trabajadoras

14. Mis alumnos creen que por culpa de los inmigrantes se perderá la cultura de España

15. Mis alumnos consideran que deben tener los mismos derechos que los demás

16. Mis alumnos consideran que los inmigrantes quieren imponer su religión

17. Mis alumnos consideran que las personas inmigrantes hacen las cosas bien

18. Mis alumnos piensan que los inmigrantes hacen que aumente la delincuencia

19. Mis alumnos consideran que gracia a ellos conocemos otras culturas y lenguas

20. Mis alumnos consideran que los inmigrantes traen enfermedades a España

21. Mis alumnos consideran que las personas inmigrantes son buena gente

22. Mis alumnos consideran que las personas inmigrantes saturan los servicios sociales

23. Mis alumnos creen que hacen los trabajos que la gente de aquí no quiere hacer

24. Mis alumnos creen que los inmigrantes son más machistas que los de aquí

25. Mis alumnos consideran que ayudan a mejorar la economía de España

26. Mis alumnos sienten simpatía por:

\begin{tabular}{|c|c|c|c|c|c|}
\hline & & & & & \\
\hline & & 2 & 3 & 4 & 5 \\
\hline - Las personas chinas & 1 & 2 & 3 & 4 & 5 \\
\hline - Las personas rumanas & 1 & 2 & 3 & 4 & 5 \\
\hline - Las personas gitanas & 1 & 2 & 3 & 4 & 5 \\
\hline - Las personas sudamericanas & 1 & 2 & 3 & 4 & 5 \\
\hline - Las personas árabes & 1 & 2 & 3 & 4 & 5 \\
\hline 27. En España viven demasiadas personas inmigrantes & 1 & 2 & 3 & 4 & 5 \\
\hline 28. Mis alumnos piensan que España es un país tolerante & 1 & 2 & 3 & 4 & 5 \\
\hline $\begin{array}{l}\text { 29. Mis alumnos piensas que las personas de origen gitano sino te la dan a la salida te la } \\
\text { dan a la entrada. }\end{array}$ & 1 & 2 & 3 & 4 & 5 \\
\hline 30. $\quad$ Mis alumnos piensan que todos los árabes son musulmanes & 1 & 2 & 3 & 4 & 5 \\
\hline 31. Mis alumnos piensas que todos musulmanes son islamistas radicales & 1 & 2 & 3 & 4 & 5 \\
\hline 32. $\quad$ Pienso que todas los musulmanes son árabes & 1 & 2 & 3 & 4 & 5 \\
\hline 33. En el AMPA hay padres de alumnos inmigrantes & 1 & 2 & 3 & 4 & 5 \\
\hline 34. Mis alumnos asisten a los cumpleaños de sus compañeros inmigrantes & 1 & 2 & 3 & 4 & 5 \\
\hline 35. Los padres se relacionan de forma positiva con otros padres de alumnos inmigrantes & 1 & 2 & 3 & 4 & 5 \\
\hline 36. Mis alumnos tienen vecinos de origen inmi & 1 & 2 & 3 & 4 & 5 \\
\hline
\end{tabular}

36. Mis alumnos tienen vecinos de origen inmigrante.

\begin{tabular}{|c|c|c|c|c|}
\hline 1 & 2 & 3 & 4 & 5 \\
\hline 1 & 2 & 3 & 4 & 5 \\
\hline 1 & 2 & 3 & 4 & 5 \\
\hline 1 & 2 & 3 & 4 & 5 \\
\hline 1 & 2 & 3 & 4 & 5 \\
\hline 1 & 2 & 3 & 4 & 5 \\
\hline 1 & 2 & 3 & 4 & 5 \\
\hline 1 & 2 & 3 & 4 & 5 \\
\hline 1 & 2 & 3 & 4 & 5 \\
\hline 1 & 2 & 3 & 4 & 5 \\
\hline 1 & 2 & 3 & 4 & 5 \\
\hline 1 & 2 & 3 & 4 & 5 \\
\hline 1 & 2 & 3 & 4 & 5 \\
\hline 1 & 2 & 3 & 4 & 5 \\
\hline 1 & 2 & 3 & 4 & 5 \\
\hline 1 & 2 & 3 & 4 & 5 \\
\hline 1 & 2 & 3 & 4 & \\
\hline
\end{tabular}




\begin{tabular}{|c|c|c|c|c|c|}
\hline 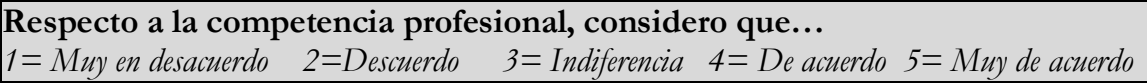 & & & & & \\
\hline 1. En clase conocemos la cultura de otros países & 1 & 2 & 3 & 4 & 5 \\
\hline 2. En clase se utiliza un lenguaje no discriminatorio & 1 & 2 & 3 & 4 & 5 \\
\hline 3. En clase se fomenta las relaciones interculturales & 1 & 2 & 3 & 4 & 5 \\
\hline 4. En clase se fomenta la tolerancia & 1 & 2 & 3 & 4 & 5 \\
\hline 5. En clase se fomenta el respeto hacia otras culturas, religiones, etc. & 1 & 2 & 3 & 4 & 5 \\
\hline 6. Se trabaja la comunicación intercultural en clase & 1 & 2 & 3 & 4 & 5 \\
\hline 7. Agrupo a mis alumnos de forma inclusiva & 1 & 2 & 3 & 4 & 5 \\
\hline 8. Estoy formado en habilidades sociales & 1 & 2 & 3 & 4 & 5 \\
\hline 9. Tengo conocimientos sobre resolución de conflictos & 1 & 2 & 3 & 4 & 5 \\
\hline 11. Tengo conocimiento de estrategias basadas en la tolerancia y en la diversidad. & 1 & 2 & 3 & 4 & 5 \\
\hline
\end{tabular}

\section{Anexo B. Guion de entrevista para profesorado y estudiantes de $3^{\circ}$ y $4^{\circ}$ ESO}

1. ¿Sabes que son los prejuicios? ¿conoces los distintos tipos de prejuicios? podrías decirme alguno

2. ¿alguna vez has escuchado comentarios como por ejemplo "los inmigrantes nos quitan el trabajo" o "deberían echarlos a todos"?

3. ¿Cómo te sientes/qué piensas cuando escuchas este tipo de comentarios?

4. ¿Consideras que los políticos españoles deben preocuparse primero por los españoles y luego por los inmigrantes?

5. En la barriada del cerezo, muy próxima al centro hay una mezquita, ¿qué te parece que las personas que practican la religión musulmana tenga su propio templo?

6. ¿Alguna vez cuando te has encontrado con alguna persona de origen gitano has pensado que te iba a robar? ¿te sientes inseguro con personas gitanas?

7. ¿Sabes que es un estereotipo?

8. ¿Cómo me describirías a una persona de color?

9. ¿Y a una persona de origen rumano?

10. ¿Tienes amigos/as gitanos, negros, rumanos, musulmanes, extranjeros...?

11. ¿Consideras que las personas que emigran lo hacen por trabajar o por recibir ayudas públicas?

12. ¿Has escuchado alguna vez que las personas de otras culturas o creencias están dispuestos a trabajar por menos dinero que los autóctonos?

13. ¿Piensas que los españoles rechazan puestos de trabajo cuando son de un salario bajo?

14. Conoces la cultura/religión/... de tus compañeros de clase

15. ¿Qué tipos de actividades interculturales realizas en clase?

16. ¿Con quién te sientas en clase? (son de tu misma cultura, raza, religión...)

17. ¿El profesorado fomenta que se relacione el alumnado autóctono con el alumnado inmigrante?

18. ¿El centro realiza actividades para dar a conocer la diversidad que existe en el centro?

19. ¿A qué se deben los principales conflictos entre los estudiantes? ¿y con los profesores? 
20. ¿Cómo crees que vive tu centro la realidad multicultural?

\section{Referencias}

Abdallah-Pretceilla, M. (2001). La educación intercultural. Barcelona: Idea Books.

Ballesteros-Moscosio, M.A. (2013). Enseñar y aprender a convivir desde el conocimiento: formación de los futuros docentes de Secundaria sobre la cuestión intercultural a través del uso de TIC. En V. Llorent \& A. El Fathi (Presidentes). Actas del Congreso Internacional Hispano-Marroqui "Imagen mediática de Marruecos en España". Tetuán, 17-19 de abril de 2013.

Cabrera, F. A., (2002). Hacia una nueva concepción de la ciudadanía en una sociedad multicultural. In M. Bartolomé (Ed). Identidad y Ciudadania. Un reto a la educación intercultural, (pp. 27-104), Madrid: Narcea.

Díaz, M.J. (Coord) (1999). Educación multicultural y aprendizaje cooperativo en contextos heterogéneos. Madrid: CIDE. Memoria de investigación.

Dietz, G. (2012). Multiculturalismo, inteculturalidad y diversidad en educación. México: Fondo de Cultura Económica.

Delors, J. (2000). La educación encierra un tesoro. Informe a la Unesco de la Comisión Internacional sobre la Educación para el Siglo XXI. Madrid: Santillana.

Escarbajal, A. (2009). Estudios de las respuestas socioeducativas ofrecidas a los inmigrantes en la Región de Murcia y propuesta formativa para Trabajadores Sociales y Educadores Sociales. Universidad de Murcia: Tesis doctoral Inédita.

Figueroa, P. (1993). Education for cultural diversity. Londres: Routledge

García, F. J. \& Pulido, R. A. (1992). Educación multicultural y antropológica de la educación. En P. Fermoso (Ed.). Educación intercultural: la Europa sin fronteras, (pp. 35-70). Barcelona; Narcea

García, J. L. (2005). Educación Intercultural. Análisis y propuestas. Revista de Educación, 336, pp. 89109.

Leiva, J. (2010). Educación intercultural y convivencia desde la perspectiva docente. Profesorado. Revista de curriculum y formación del profesorado, 14(3), pp. 251-274.

Malazonia, D., Maglakelidze, S., Chiabrishvili, N., \& Gakheladze, G. (2017). Factors of students ${ }^{\text {ee }}$ intercultural competence development $t$ in the context of Georgia. Cogent education, (4), pp. 1-17.

Martínez, M. (2018). La importancia de introducir la competencia intercultural en la Educación Superior: Propuesta de actividades prácticas. Revista Electrónica de Educación, 22(1)

Morales, S. M. (2007). La educación de competencias para la convivencia intercultural. Tesis doctoral. Universidad de Valencia. Recuperado el 29 de abril de 2011 de http//www.resisenxarxa.net/TESIS_UV/AVAILABLE/ TDX-0520108-150238/morales.pdf.

Pech, C. \& Rizo, M. (2014). Interculturalidad miradas críticas. Barcelona: Institut de la Comunicació, Universitat Autónoma de Barcelona.

Pozuelos, F. J. (2008). Currículum e interculturales: Aportaciones para una educación transformadora. In Jiménez, A. \& Cruz, M. R. (Coord.) Integración de menores inmigrantes en contextos educativos plurales, pp. 71-88. Huelva: ACCEM.

Quilaqueo, D., \& Torres, H. (2013). Multiculturalidad e interculturalidad: desafíos epistemológicos de la escolarización desarrollada en contextos indígenas. ALPHA, pp. 285-300.

Saez, R. (2006). La educación Intercultural. Revista de educación, 339, pp. 859-881. 